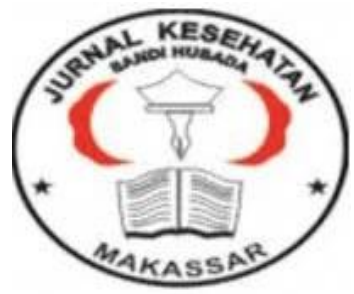

\author{
Jurnal Ilmiah Kesehatan Sandi Husada \\ hhttps://akper-sandikarsa.e-journal.id/JIKSH \\ Volume 9, Nomor 2, Desember 2020, pp 983-987 \\ p-ISSN: 2354-6093 dan e-ISSN: 2654-4563 \\ DOI: $10.35816 /$ jiskh.v10i2.436
}

\title{
Whatsapp Sebagai Pendidikan Kesehatan Dalam Meningkatkan Pengetahuan Ibu Tentang Mp-Asi
}

Whatsapp as Health Education in Increasing Mother's Knowledge About Mp-Asi

\section{Dwi Riyan Ariestantia1, Purwaningtias Budi Utami2}

1,2 Sekolah Tinggi Ilmu Kesehatan Mutiara Mahakam Samarinda

\begin{tabular}{l}
\multicolumn{1}{c}{ Artikel info } \\
Artikel history: \\
Received; Agustus 2020 \\
Revised: September 2020 \\
Accepted; Oktober 2020
\end{tabular}

\begin{abstract}
.
There are various ways to convey information about complementary foods, including through the delivery of health education with counseling. Extension with the lecture method is the method most often carried out and is limited by time, however the WhatsApp media is a medium of communication that is used daily by many people in almost all countries. Messages that can be sent can be in the form of written messages, images or sounds so that this media is very suitable to be used as a media for health education in order to increase public knowledge in general and especially for mothers about complementary breastfeeding. This study aims to determine the difference in the effectiveness of counseling on complementary foods using lectures and WhatsApp methods at the UPTD Puskesmas Sempaja Samarinda. This research method uses a Quasi-experimental plan with pretest-posttest control group design. This research was conducted on 03-16 April 2020. The study population was mothers who had children aged 6 months to 2 years. The sample in this study were 66 respondents consisting of 33 intervention groups and 33 control groups. The results of statistical tests show that there are differences before and after giving intervention via WhatsApp with a p-value of 0,000. The conclusion in this study is that there is an increase in respondent knowledge after counseling, but in the intervention group there is a more significant increase in knowledge.
\end{abstract}

\begin{abstract}
Abstrak
Berbagai cara dalam menyampaikan informasi tentang MP ASI, diantaranya melalui penyampaian pendidikan kesehatan dengan penyuluhan. Penyuluhan dengan metode ceramah adalah cara yang paling sering dilakukan dan terbatas oleh waktu, namun media whatsapp adalah media komunikasi yang digunakan sehari-hari oleh banyak orang di hampir semua Negara. Pesan yang dikirimkanpun dapat berupa pesan tertulis, gambar maupun suara sehingga media ini sangat cocok untuk dijadikan sebagai media pendidikan kesehatan guna meningkatkan pengetahuan masyarakat pada umumnya dan khususnya pada ibu tentang MP ASI. Penelitian ini bertujuan untuk mengetahui perbedaan keefektifan penyuluhan tentang MP-ASI menggunakan metode ceramah dan whatsapp di UPTD Puskesmas Sempaja Samarinda. Metode penelitian ini menggunakan Quasi eksperimen dengan rencana pretest-posttest control group design. Penelitian ini dilakukan tanggal 03 - 16 April 2020. Populasi Penelitian adalah ibu yang memiliki anak usia 6 bulan sampai dengan 2 tahun. Sampel dalam penelitian ini adalah 66 responden yang terdiri dari 33 kelompok intervensi dan 33
\end{abstract}


kelompok kontrol. Hasil uji statistic menunjukkan bahwa terdapat perbedaan sebelum dan sesudah pemberian intervensi melalui whatsapp dengan nilai $p$ value 0,000. Kesimpulan pada penelitian ini yaitu terjadi peningkatan pengetahuan respnden setelah dilakukan penyuluhan, akan tetapi pada kelompok intervensi terjadi peningkatan pengetahuan yang lebih signifikan.

\author{
Keywords: \\ Whatsapp; \\ Pengetahuan; \\ MP-ASI;
}

Coresponden author:

Email: dwi.riyanmelon@gmail.com

artikel dengan akses terbuka dibawah lisensi CC BY -4.0

\section{Pendahuluan}

Pemberian Makanan Pendamping ASI (MP-ASI) dimulai ketika ASI dianggap tidak mencukupi lagi untuk memenuhi kebutuhan nutrisi bayi, sehingga diperlukan asupan lain untuk mendukung pertumbuhan dan perkembangan bayi (Abdurahman et al., 2019). Pemberian ASI dan makanan pendamping yang tidak adekuat serta tingginya angka penyakit menular dan perlambatan pertumbuhan serta perkembangan (Hariani et al., 2016; Romero-Velarde et al., 2016). WHO mencatat bahwa kejadian stunting anak dibawah lima tahun di masyarakat dunia lebih dari 20\%, hal ini menimbulkan masalah kesehatan. Makanan tambahan yang kurang baik atau tidak seimbang (tidak atau kurang mengandung seng) dapat mencetuskan kejadian stunting lebih besar (Uwiringiyimana et al., 2019). Tercatat bahwa sebesar 51\% angka kematian bayi dan balita disebabkan oleh pneumonia, diare, campak, malaria dan sebagian besar angka kematian tersebut berhubungan dengan masalah gizi (54\%) (Sakti et al., 2013). Mendapatkan asupan nutrisi yang baik dan cukup adalah hak dasar dari anak, sedangkan pengetahuan dari ibu tentang nutrisi yang baik juga menentukan pemberian MP-ASI. Dari data Surfei Demografi dan Kesehatan Indonesia (SDKI) diketahui bahwa bayi berusia dibawah $4-6$ bulan telah diberi MP-ASI $(12,8 \%)$. Sehingga pengetahuan ibu tentang MP-ASI sangatlah penting (Sakti et al., 2013).

Usaha dalam meningkatkan status kesehatan bayi/anak melalui peningkatan pengetahuan masyarakat khususnya ibu dalam pemberian MP-ASI adalah hal yang sangat penting dan tidak dapat diabaikan. Ketidak pahaman ibu tentang pemberian MP-ASI serta adanya kebiasaan yang merugikan baik secara langsung maupun tidak langsung adalah penyebab utama terjadinya masalah ketidak seimbangan gizi pada bayi/anak dengan usia dibawah dua tahun (Febry and Destriatania, 2016). Informasi merupakan hal yang sangat penting, setiap orang berupaya agar dapat mengakses sebuah informasi yang dibutuhkan. Dengan pesatnya perkembangan teknologi maka pertukaran informasi antara satu dengan yang lain dapat dilakukan dalam hitungan detik salah satunya inovasi dalam interaksi social yaitu media social. Media social saat ini tidak hanya sekedar untuk berkomunikasi dan menjalin hubungan akan tetapi dapat juga dijadikan sebagai penyampai informasi (Rathbone et al., 2020)

Whatsapp adalah aplikasi media komunikasi yang sedang populer yang secara instan dapat menyampaikan pesan dikalangan masyarakat belakangan ini. Whatsapp biasa digunakan untuk berkomunikasi secara pribadi antara dua orang atau lebih yang sedang tidak berada disatu tempat yang sama. Whatsapp banyak digunakan untuk tujuan-tujuan social, aplikasi media komunikasi ini telah terhubung dalam praktik kerja organisasi kesehatan, whatsapp dapat dijadikan media bertukar komunikasi tentang keadaan pasien dan pengajuan pertanyaan-pertanyaan klinis. Media whatsapp dapat di jadikan sebagai 
alat penyampai pendidikan kesehatan kepada masyarakat, dan masyarakatpun dapat memberikan pertanyaan seputar masalah yang dikeluhkannya (Rathbone et al., 2020). Penelitian yang dilakukan di Banda Aceh pada tahun 2015 didapatkan hasil bahwa proporsi anak dengan umur dibawah dua tahun yang mengalami stunting sebesar $58,3 \%$, diare sebesar 28,2\%, dikarenakan pemberian MP-ASI yang kurang baik (Al-rahmad et al., 2015).

\section{Metode}

Penelitian ini menggunakan Quasi Experimental Design (pretest-posttest with control group design) dengan metode kualitatif. Penelitian dilakukan di UPTD Puskesmas Sempaja Kota Samarinda Provinsi Kalimantan Timur pada tanggal 03 sampai dengan 16 April 2020. Populasi penelitian ini adalah semua ibu yang memiliki anak usia 6 bulan sampai dengan 2 tahun dan menjadi warga diwilayah kerja Puskesmas Sempaja. Jumlah sampel dihitung dengan menggunakan rumus $n=22 Z_{1}-\alpha+Z_{1}-\beta^{2}(\mu 1-\mu 2)^{2}$ sehingga jumlah sampel yang diperoleh adalah 30 sampel, akan tetapi guna menghindari kejadian dropout perhitungan besar sampel ditambah 10\%, sehingga besar sampel minimal adalah 33 ibu setiap kelompok. Jadi total jumlah sampel $66 \mathrm{ibu}$.

\section{Hasil Dan Pembahasan}

Tabel 1. Karakteristik Responden ( $\mathrm{n}=66)$

\begin{tabular}{ccc}
\hline Karakteristik & n & \% \\
\hline Umur (Tahun) & & \\
$17-25$ & 17 & 25,6 \\
$26-35$ & 28 & 42,4 \\
$36-45$ & 21 & 32 \\
\hline Pendidikan & & \\
Tidak Sekolah & 0 & 0 \\
Lulus SD & 6 & 9,2 \\
Lulus SMP & 10 & 15 \\
Lulus SMA & 33 & 50 \\
Lulus PT & 17 & 25,8 \\
\hline Pekerjaan & & \\
Ibu Rumah Tangga & 49 & 74,2 \\
Pegawai Swasta & 5 & 7,6 \\
Wiraswasta & 10 & 15,2 \\
PNS & 2 & 3 \\
\hline Paritas & & \\
Primi & 22 & 33,4 \\
Multi & 42 & 63,6 \\
Grandle & 2 & 3 \\
\hline Sumber: Data Primer 2020 &
\end{tabular}

Tabel 1 menunjukkan pada kelompok intervensi dari 66 subjek, sebagian besar responden berusia 26 - 35 tahun $(42,4 \%)$ dan sebagian kecil berusia 17-25 tahun (25,6\%), untuk jenjang pendidikan sebagian besar responden lulus SMA (50\%) dan sebagian kecil adalah lulus SD $(9,2 \%)$, sebagian besar responden tidak bekerja (ibu rumah tangga) $(74,2 \%)$ dan sebagian kecil bekerja sebagai PNS (3\%), serta paritas responden sebagian besar adalah multi $(63,6 \%)$ dan sebagian kecil Grandle (3\%). 
Tabel 2. Perbedaan Pengetahuan Kelompok Intervensi dan Kelompok Kontrol

\begin{tabular}{cccc}
\hline $\begin{array}{c}\text { Hasil } \\
\text { Statistik }\end{array}$ & Sebelum & Sesudah & $\begin{array}{c}\text { p- } \\
\text { value* }\end{array}$ \\
\hline $\begin{array}{c}\text { Intervensi } \\
\text { Mean } \pm \text { SD }\end{array}$ & $11,91 \pm 1,721$ & $14,00 \pm 2,151$ & 0,000 \\
\hline $\begin{array}{c}\text { Kontrol } \\
\text { Mean } \pm \text { SD }\end{array}$ & $11,61 \pm 1,657$ & $12,55 \pm 2,108$ & 0,002 \\
\hline * hasil uji statistik sebelum dan sesudah intervensi
\end{tabular}

Tabel 2 menunjukkan bahwa nilai rata-rata dan standar deviasi skor pengetahuan kelompok intervensi sebelum dan sesudah kelas whatsapp sebesar 11,91 $\pm 1,721$ menjadi $14,00 \pm 2,151$ Dengan nilai $p$ value $0,000<0,05$ yang berarti ada perbedaan yang signifikan dari pengetahuan sebelum dan sesudah dilakukan intervensi melalui kelas MP-ASI (Whatsapp), sedangakan rata-rata dan standar deviasi skor pengetahuan kelompok kontrol sebelum dan sesudah penyuluhan sebesar 11,61 $\pm 1,657$ menjadi $12,55 \pm 2,108$ dengan nilai $\mathrm{p}$ value $0,002<0,05$ yang berarti ada perbedaan pengetahuan kelompok kontrol sebelum dan sesudah dilakukan penyuluhan dengan media power point menggunakan metode ceramah.

Pada penelitian ini, terdapat dua kelompok uji yaitu kelompok kontrol dan kelompok intervensi, dimana jumlah responden masing-masing kelompok adalah 33 orang. Sebelum intervensi (penyuluhan atau kelas MP-ASI melalui whatsapp), pada setiap kelompok dilakukan pretest diperoleh hasil yang sama antara kelompok kontrol dengan kelompok intervensi. Pada setiap kelompok Penelitian ini menunjukkan bahwa terdapat perbedaan pengetahuan responden sebelum dan sesudah intervensi (pemberian informasi tentang MP-ASI) baik kelompok kontrol maupun kelompok intervensi.

Berbagai cara yang memiliki keterkaitan antara keinginan pencapaian dalam memberikan edukasi dan perubahan kognitif serta cara pandang sesorang, dapat dilakukan dengan metode pendidikan kesehatan yang mengikuti perkembangan zaman saat ini. Disebagian wilayah akses terhadap jaringan internet sudah cukup memadai seperti halnya penggunaan wifi, namun hal ini masih membutuhkan tempat. Sedangkan jaringan internet melalui ponsel sudah hampir seluruh masyarakat telah memiliki untuk mendapatkan informasi yang cepat, cukup hanya dengan bermodalkan android, paket data sudah dapat menjangkau media media sosial.

Salah satu media sosial yang saat ini marak digunakan adalah whatsapp, sehingga hal ini memungkinkan untuk dilakukan sebuah edukasi pendidikan kesehatan, karena cukup dengan dirumah, antara fasilitator dan peserta dapat terus berkomunikasi dan memantau. Cara pemberian informasi tentang MP-ASI ini berbeda setiap kelompoknya, pada kelompok kontrol diberikan informasi tentang MP-ASI dengan cara Penyuluhan (ceramah) menggunakan media power point, sedangkan kelompok intervensi diberikan informasi tentang MP-ASI dengan cara membuat group whatsapp dan pemberian informasi tentang MP-ASI ini diberikan secara rutin selama 2 minggu berturut-turut. Hal ini sejalan dengan teori yang dikemukakan oleh Dewi dan Wawan (2010) yang menyatakan bahwa pengetahuan dipengaruhi oleh teknik penyampaian materi atau informasi. 


\section{Simpulan Dan Saran}

Berdasarkan hasil penelitian yang telah dilaksanakan dapat disimpulkan bahwa ada perbedaan yang sangat signifikan nilai rata-rata skor pengetahuan kelompok kontrol dan kelompok intervensi. Kedua kelompok ini mengalami perubahan pengetahuan setelah dilakukan intervensi, akan tetapi pada kelompok kontrol peningkatannya tidak sesignifikan kelompok intervensi, hal ini kemungkinan dikarenakan penyuluhan dengan metode ceramah hanya dilaksanakan satu kali, sedangkan kelompok intervensi dilaksanakan secara terus menerus selama 2 minggu.

\section{Daftar Pustaka}

Abdurahman, A. A., Chaka, E. E., Bule, M. H., \& Niaz, K. (2019). Magnitude and determinants of complementary feeding practices in Ethiopia: A systematic review and metaanalysis. Heliyon, 5(7),

Al-Rahmad, A. H., Miko, A., \& Hadi, A. (2013). Kajian stunting pada anak balita ditinjau dari pemberian ASI eksklusif, MP-ASI, status imunisasi dan karakteristik keluarga di Kota Banda Aceh. J Kesehatan Ilmiah Nasuwakes, 6(2), 169-184.

Febry, F., \& Destriatania, S. (2016). Analisis Pemberian MP-ASI Dengan Status Gizi Pada Anak Usia 12-24 Bulan Di Wilayah Kerja Puskesmas Lesung Batu, Empat Lawang. Jurnal Ilmu Kesehatan Masyarakat, 7(2), 139-149.

Hariani, R. E., Amareta, D. I., \& Suryana, A. L. (2016). Pola pemberian asi dan makanan pendamping asi terhadap grafik pertumbuhan pada kartu menuju sehat (kms). Jurnal Ilmiah Inovasi, 16(1).

Rathbone, A. P., Norris, R., Parker, P., Lindsley, A., Robinson, A., Baqir, W., \& Husband, A. (2020). Exploring the use of WhatsApp in out-of-hours pharmacy services: A multisite qualitative study. Research in Social and Administrative Pharmacy, 16(4), 503510.

Romero-Velarde, E., Villalpando-Carrión, S., Pérez-Lizaur, A. B., Iracheta-Gerez, M. de la L., Alonso-Rivera, C. G., López-Navarrete, G. E., ... Pinacho-Velázquez, J. L. (2016). Guidelines for complementary feeding in healthy infants. Boletín Médico Del Hospital Infantil de México (English Edition), 73(5), 338-356.

Sakti, R. E., Hadju, V., \& Rochimiwati, S. N. (2013). Hubungan Pola Pemberian MP-ASI dengan Status Gizi Anak Usia 6-23 Bulan di Wilayah Pesisir Kecamatan Tallo Kota Makassar Tahun 2013. Jurnal MKMI K, 21109274, 0-2.

Uwiringiyimana, V., Ocké, M. C., Amer, S., \& Veldkamp, A. (2019). Predictors of stunting with particular focus on complementary feeding practices: A cross-sectional study in the northern province of Rwanda. Nutrition, 60, 11-18. 